\title{
Is the Future of Higher Education Learning "Blended": Using Technology to Enhance the Learning Experience
}

\author{
Peter Newcombe \\ The University of Queensland, Australia \\ newc@psy.uq.edu.au
}

\begin{abstract}
Active learning involves an engagement with the learning materials that is greater than merely passively sitting in a lecture theatre. Blended learning models that include an integration of active face-to-face on-campus learning activities with well-developed online learning activities can assist students to have a more complete learning experience. Student surveys tell us that students themselves want a digital experience to supplement their on-campus learning. Employers have an ever increasing need for graduates with digital literacy skills. Universities are beginning to acknowledge this changing face of higher education delivery. This paper will discuss these issues along with providing steps to ensure that our staff and students are equipped to best take advantage of this new and powerful world that encompasses digital and face-to-face learning.
\end{abstract}

Keywords: higher education learning, blended learning, using technology, learning experience

\section{INTRODUCTION}

"I hear and I forget; I see and I remember; I do and I understand" (Old Chinese Proverb). It has long been recognized that simply listening to someone else talk is less effective for learning than doing things oneself or engaging in activities. When a student is sitting in a passive lecture (with no active learning, no immediate requirement to perform, and no discussion), their mind is likely to wander. With learning tasks that make few demands (e.g., passive lecture), executive control tends to maximize the occurrence of taskunrelated thought both inside (Rummel \& Boywitt, 2014) and outside of the laboratory (Kane et al., 2007). This "mind wandering" has been linked to poor outcomes in a wide range of tasks (e.g., impairs comprehension during reading: Jackson \& Balota, 2012) and during lectures (Farley, Risko, \& Kingstone, 2013).

In contrast, when students are engaged in time-sensitive, active learning, their mind is less likely to wander. Research shows that when learning makes consistent demands on external attention (e.g., a classroom with active learning, or learning online in small chunks with regular self-assessment under time pressure), students with good executive control tend to limit the occurrence of task-unrelated self-generated thought - that is, they are less likely to mind wander (McVay \& Kane, 2011).

Active learning refers to a range of teaching approaches that encourage active engagement of learners with course material, one another, and/or lecturers. It contrasts with "passive learning" of lecture-based or talking head-style instruction. It encompasses various educational approaches including collaborative learning, cooperative learning, experiential learning project-based learning, problembased or inquiry-based learning, peer-led instruction, role-playing and simulation. Research connecting "active learning" classrooms with student learning shows that students in active learning: (1) outperform their peers in traditional classrooms; (2) exceed their own grade expectations as predicted by standardized test scores; and (3) show significant student learning gains over using a lecture-based approach in the same space (Baepler et al., 2016). A well cited 2014 metastudy by Freeman et al. analyzed 225 previous studies of teaching in science, engineering, and mathematics. The results showed that, when active learning was employed, average examination scores improved by approximately $6 \%$. Further, students taught by traditional lecturing were 1.5 times more likely to fail than students taught through active learning. In light of these results, the authors recommended abandoning traditional lecturing in favor of active learning.

Active learning approaches are evidenced with "blended" learning practices that combine in-class activities with the delivery of online resources. Blended learning involves integrating and interspersing opportunities for student engagement through face-toface engagement alongside interactive online activities. It draws on technology-mediated instruction, where all participants in the learning process are separated by distance some of the time, alongside traditional face-toface modes of instruction. The terms blended learning, mixed-mode, hybrid, and flipped courses are often used interchangeably (Mean, Toyama, Murphy, \& Baki, 2013) as are the terms elearning, computer-aided instruction, educational technology, computer-assisted instruction (Siemens, Gašević, \& Dawson, 2015).

\section{BLENDED LEARNING PRACTICES}

Blended learning instructional practices mirror effective practices within both face-to-face and online modes. Research indicates that different modes of learning are best suited for achieving particular learning outcomes. For example, problem-based faceto-face learning has a positive effect on skills, and a negative effect on knowledge (Gijbels et al., 2005) while effectively designed online learning facilitates the development of factual and declarative knowledge (Rowe, Frantz, \& Bozalek, 2012). The hypothesis that different instructional modes are suited for different tasks is further confirmed by studies that show that the same amount of time spent on a task will impact the learning outcome in the online mode, but will not have a comparable impact in the face-to-face setting (Means et al., 2013). This reinforces McGee and Reis's (2012) 
recommendation that blended learning include active learning and varied interactivity.

Although blended course design involves understanding the differences between face-to-face and online modes of learning, it must also acknowledge that the different modes do have similarities. They both require clearly defined course objectives, which are the foundation for the course activities, assignments, and assessments. There is strong evidence of the essential role that feedback plays in learning across both modes. As expected, prompt feedback is a suggested practice in blended learning settings (McGee \& Reis, 2012). They also require extra attention to be paid to developing additional student support to reduce the dependence on the teacher and to assist with selfregulated learning skills (Bernard et al., 2014).

A number of systematic analyses and metaanalyses have addressed the effectiveness of blended learning. Paul (2001) concluded that face-to-face with online enhancement was $11 \%$ more effective than faceto-face alone (outcomes of perceptual skills, intellectual skills, motor skills, attitudes). A 2004 metastudy by Prince found strong support for active, collaborative, cooperative, and problem-based learning. Across 52 studies, Zhao, Lei, Yan, and Lai (2005) found a 0.49 effect size for online learning mixed with face-to-face instruction (i.e., a greater achievement gain for blended learning). Bernard et al. (2014) found that, across 96 studies, blended learning conditions exceeded face-to-face conditions on any measure of academic performance (effect size 0.33).

The use of technology in blended learning courses for communication, for presentation, for searching, for knowledge, information and content has varying effects on academic achievement. For example, technology used to provide cognitive support has a much higher moderating effect on achievement in blended learning than does technology provided for content/presentational support or technology used to facilitate communication among peers and with the lecturer (Bernard et al., 2014). These results suggest that technological tools have varying power in their influence on student learning and these must be considered in the development of blended learning online tools.

\section{STUDENTS AND EMPLOYERS}

For blended learning to be successful it must meet the demands, not only of higher education teams but also, of the students and their prospective employers. Such a significant change in pedagogical practice demands a careful analysis of student needs and career demands. Recent surveys at the University of Queensland (UQ: 2015, 2018) clearly highlight students' interest in blended learning and identify the advantages that students see in this approach.

From a sample of 7,005 students at the UQ (2015), 70\% responded that they would "appreciate courses designed as a mix of online lectures and interactives classes on campus". Where learning was distributed across face-to-face and online activities, students felt more independent when digital technologies were used (79\%), could fit learning into life more easily $(76 \%)$, enjoyed learning more $(63 \%)$, and understood content better $(60 \%)$ (UQ, 2018, n = 9,978 ). Moreover, students expected recording of oncampus lectures to be available online within 4-8 hours of the live event (UQ, 2017). Recorded lectures are utilised 24 hours/day at UQ with peak periods during revision week $(165,000$ views) followed by exam week (137,000 views).

Changing student expectations are highlighted by a recent report by Ernst \& Young Global Limited in their 2018 report. They identified quantitative variation between the expectations of current and prospective students. Of current students surveyed, $22 \%$ preferred the majority of their degree to be delivered online compared with $42 \%$ of prospective students. The availability of online study was seen as important by $43 \%$ of current students rising to $58 \%$ of prospective students. When questioned about whether they thought online learning to be effective, only $37 \%$ of current students thought so compared with $49 \%$ of prospective students. Clearly, students of the future will demand an online learning experience.

Student interest and demand for online learning is mirrored in enterprise skills required by employers as evidenced in their position advertisements. The Foundation for Young Australians (2017) reported a 212\% increase over the last 3 years in advertisements for positions requiring digital literacy skills. Corresponding increases in the requirements for critical thinking skills (158\%) and creativity (65\%) reflect a need for students to engage in active learning through their education.

\section{LOOKING AHEAD}

To create a flexible and active study experience for students, the goal of a blended learning approach, requires a commitment of resources and staff. A high value on-campus experience that is augmented by high quality online activities demands a strategic approach by universities. The necessary expertise in designing quality digital experiences across both the digital and face-to-face space involves a significant investment in instructional design and learning science (Bailey, Vaduganathan, Henry, \& Pugliese, 2018). This can be achieved through creating a central team of experts in blended pedagogy who can co-create the learning with faculty and then assist in maintaining momentum. Faculty must be engaged with, and be true partners in, the design, development, and maintenance of digital learning activities that integrate with face-to-face learning experiences. This will involve joint participation in decision making that captures faculty expertise with content and student cohort dynamics along with the expertise of digital learning specialist, desktop publishers, and audiovisual professionals. Further, faculty should be provided with opportunities for professional development that will help to foster a culture of pedagogical innovation.

Learning science identifies the frameworks for design and development of both on-campus and online learning experiences. But the digital world now provides significant opportunities to explore learning 
data and reporting systems that can guide course improvements. Data can be used to inform course designers, coordinators, and teachers that pedagogical and subject matter objectives are being met. It can empower the teacher to personalise learning experiences and feedback quickly and effectively, even in large enrolment courses, leading to improved student satisfaction. It can provide the tools to evidence quality in the course delivery. It provides a platform to integrate research and practice in learning innovation that will lead to better informed pedagogical decision making.

Above all, support structures for students need to be provided to give them the skills to learn, engage and survive in a blended world of learning. The digital capabilities of the young are sometimes more assumed than real. Digital learning requires a set of skills that involve a sophisticated level of digital literacy. Not achieving a competency in these skills will hinder student learning progress. Digital literacy modules (e.g., online searching, online presentations, academic integrity) may need to be included within courses or as stand-alone "micro-courses" to equip students to better engage in this new world of learning.

\section{CONCLUSION}

Blended learning has been consistently found to be as, or more effective than online or purely faceto-face learning. (Siemens et al., 2015). Students are demanding greater access to online learning and flexibility with access to learning materials. More and more, employers are requiring job applicants to have digital technology skills. The future of higher education is indeed "blended".

\section{REFERENCES}

[1] Baepler, P., et al. 2016. A Guide to Teaching in the Active Learning Classroom: History, Research, and Practice. Stylus Publishing.

[2] Bailey, A., Vaduganathan, N., Henry, T., \& Pugliese, L. 2018. Making Digital Learning Work: Success Strategies from Six Leading Universities and Community Colleges. The Boston Consulting Group.

[3] Bernard, R. M., Borokhovski, E., Schmid, R. F., Tamim, R. M, \& Abrami, P. C. 2014. A Meta-Analysis of Blended Learning and Technology use in HIGHER education: From the General to the Applied. Journal of Computing in Higher Education, 26(1), 87-122. doi:10.1007/s12528-013-9077-3

[4] Ernst \& Young Global Limited (EYGL). 2018. Can the Universities of Today Lead Learning for Tomorrow? Retrieved from: http://cdn.ey.com/echannel/au/en/industries/governmen t-public-sector/ey-university-of-the-future-2030/EYuniversity-of-the-future-2030.pdf

[5] Farley, J., Risko, E. F., \& Kingstone, A. 2013. Everyday Attention and Lecture Retention: The Effects of Time, Fidgeting, and Mind Wandering. Frontiers in Psychology, 4, 619.

[6] Foundation for Young Australians. 2017. The New Basics: Big Data Reveals the Skills Young People Need for the New Work Order. Sydney: AlphaBeta.

[7] Freeman, S., et al. 2014. Active Learning Increases Student Performance in Science, Engineering, and Mathematics. Proceedings of the National Academy of
Sciences of the United States of America (Comment), vol. $111 \quad$ no. 23. http://www.pnas.org/content/111/23/8410.

[8] Gijbels, D., Dochy, F., Van den Bossche, P., \& Segers, M. 2005. Effects of Problem-Based Learning: A MetaAnalysis from the Angle of Assessment. Review of Educational Research, 75(1), 27-61. doi: 10.3102/00346543075001027.

[9] Jackson, J. D., \& Balota, D. A. 2012. Mind-Wandering in Younger and Older Adults: Converging Evidence from the Sustained Attention to Response Task and Reading for Comprehension. Psychology and Aging, 27, 106-119.

[10] Kane, M. J., Brown, L. H., McVay, J. C., Silvia, P. J., Myin-Germeys, I., \& Kwapil, T. R. 2007. For Whom the Mind Wanders, and When: An ExperienceSampling Study of Working Memory and Executive Control in Daily Life. Psychological Science, 18, 614621.

[11] McGee, P., \& Reis, A. 2012. Blended Course Design: A Synthesis of Best Practices. Journal of Asynchronous Learning Networks, 16(4), 7-22.

[12] McVay, J. C., \& Kane, M. J. 2011. Why Does Working Memory Capacity Predict Variation in Reading Comprehension? On the Influence of Mind Wandering and Executive Attention. Journal of Experimental Psychology General, 141, 302-320.

[13] Means, B., Toyama, Y., Murphy, R., \& Baki, M. 2013. The Effectiveness of Online and Blended Learning: A Meta-Analysis of the Empirical Literature. Teachers College Record, 115(3), 1-47. Retrieved from https://www.tcrecord.org/library/Abstract.asp?ContentI $\mathrm{d}=16882$

[14] Paul, D. S. 2001. A Meta-Analytic Review of Factors that Influence the Effectiveness of Web-Based Training within the Context of Distance Learning. Texas A\&M University.

[15] Prince, M. 2004. Does Active Learning Work? A Review of the Research. Journal of Engineering Education, 93(3), 223-231.

[16] Rowe, M., Frantz, J., \& Bozalek, V. 2012. The Role of Blended Learning in the Clinical Education of Healthcare Students: A Systematic Review. Medical Teacher, 34(4), 216-221. doi: 10.3109/0142159X.2012.642831.

[17] Rummel, J., \& Boywitt, C. D. 2014. Controlling the Stream of Thought: Working Memory Capacity Predicts Adjustment of Mind-Wandering to Situational Demands. Psychonomic Bulletin and Review, 21, 13091315.

[18] Siemens, G., Gašević, D., \& Dawson, S. 2015. Preparing for the Digital University: A Review of the History and Current State of Distance, Blended, and Online Learning. Athabasca University. Retrieved from https://linkresearchlab.org/PreparingDigitalUniversity.p df.

[19] University of Queensland. 2015. Student Strategy Survey. Unpublished data.

[20] University of Queensland. 2017. Final evaluation report for UQ Lecture Capture. Learning and Research Services.

[21] University of Queensland. 2018. 2018 UQ Student Technology Survey. Unpublished Data.

[22] Zhao, Y., Lei, J., Yan, B., \& Lai, C. 2005. What Makes the Difference? A Practical Analysis of Research on the Effectiveness of Distance Education. Teacher's College Record, 107, 1836-1884. 